\title{
A pouca visibilidade da mulher na toponímia de Araçuaí-MG
}

\author{
Shirlene Aparecida da Rocha ${ }^{\mathrm{i}}$
}

\begin{abstract}
RESUMO
O objetivo do presente estudo foi analisar os logradouros da cidade (ruas, praças e avenidas) de Araçuaí-MG que recebem nomes de pessoas, a fim de verificar a (in)visibilidade de nomes femininos na escolha dos topônimos, tendo em vista a importância da mulher para a formação do município. Como embasamento teórico, foram consultados trabalhos dos autores Vasconcelos (1928), Jonasson (1994), Dick (1990,1992, 1996), Faria (2017). Para a coleta de dados, foram consultados mapas e relatórios oficiais do município, que forneceram o total de 174 logradouros com nomes de pessoas, acompanhados ou não de títulos. Como resultado, observou-se que, dos 174 logradouros da cidade com nomes de pessoas, são 38 femininos e 136 masculinos. Dessa maneira, comprova-se que, também na escolha de topônimos, a desigualdade de gênero se faz presente.
\end{abstract}

Palavras-chave: Toponímia; Mulher; Araçuaí.

\begin{abstract}
This study aims to analyze the city locations (streets, squares and avenues) of AraçuaíMG that receive names of people, in order to verify the (in)visibility of female names in the choice of toponyms, given the importance of women for the formation of the municipality. As a theoretical basis, we consulted the works from Vasconcelos (1928), Jonasson (1994), Dick (1990,1992, 1996) and Faria (2017). For data collection, maps and official reports of the municipality were consulted, which provided a total of 174 locations with names of people, with or without titles. As a result, it was observed that, of the 174 locations in the city with names of people, 38 are female and 136 males. This way, it is proved that, even in the choice of toponyms, gender inequality is present.
\end{abstract}

Keywords: Toponymy; Woman; Araçuaí.

\footnotetext{
${ }^{i}$ Doutoranda em Estudos Linguísticos pela Universidade Federal de Minas Gerais, Mestre em Linguística e Língua Portuguesa pela Pontifícia Universidade Católica de Minas Gerais e professora de Ensino Básico, Técnico e Tecnológico do Instituto Federal do Norte de Minas Gerais, Campus Araçuaí. E-mail: shirlene.rocha@ifnmg.edu.br
} 


\section{INTRODUÇÃO}

Trazer à tona a divisão de espaços sociais entre homens e mulheres não é nenhuma novidade, tendo em vista que, desde os primórdios, cabia aos homens sair de casa para buscar recursos que garantissem a sobrevivência da família e às mulheres cuidar da casa e dos filhos. Os homens eram considerados como a parte forte e a mulher a parte frágil da vida em sociedade. No entanto, desde os textos bíblicos, já é possível obter registros que demonstram a força da figura feminina:

$\mathrm{O}$ rei do Egito dirigiu-se, igualmente, às parteiras dos hebreus (uma se chamavam Sefra e a outra, Fua) e disse-lhes: "Quando assistirdes às mulheres dos hebreus, e as virdes sobre o leito, se for um filho, matai-o, mas se for uma menina deixai-a viver". Mas as parteiras temiam a Deus e não executaram as ordens do rei do Egito, deixando viver os meninos. (BÍBLIA, Êxodo 1, 15-17)

A princípio, pode-se pensar que a não exigência da morte das meninas era um privilégio. No entanto, por trás disso, estava o interesse do representante do Império Egípcio na escravidão do povo hebreu. Mas, nesse trecho, a força e a coragem das mulheres ficam demonstradas por meio das experiências das parteiras do Egito, que mesmo recebendo ordens do faraó para que matassem todos os meninos que nascessem, decidiram contrariá-lo e traçar uma estratégia para mantê-los vivos em solidariedade ao povo hebreu. Essa força da mulher, depois de muitos anos, foi sendo aos poucos revelada através de várias conquistas femininas.

Conforme Ana Luiza de Souza (2011), o modelo de família patriarcal foi abalado com as mudanças vividas no Brasil, quando a mulher também assumiu o papel de trabalho na rua, entendido como trabalho fora de casa, diminuindo um pouco a demarcação destes espaços.

No entanto, é indubitável que ainda persiste a desigualdade de gênero no contexto da sociedade patriarcal vigente. Um exemplo é que, ao assumir funções laborais fora de casa a fim de contribuir para o sustento da família, a mulher simplesmente acumulou mais uma função. Conforme uma ampla pesquisa de 2003, realizada por Araújo e Scaflon (2005) em 2000 domicílios de 24 estados brasileiros, a maior parte do trabalho doméstico continua sendo atribuído à mulher. A participação do 
homem ao executar alguma atividade doméstica ainda é vista apenas como uma ajuda à função que é primordialmente feminina.

Essa desigualdade pode ser demonstrada por diversos estudos. Em 2017, por exemplo, a World Economic Forum (WEF) elaborou a Global Gender Gap (diferenças globais entre gêneros). A partir dos dados analisados, o estudo demonstrou que serão necessários, no mínimo, 100 anos para que a equidade entre homem e mulher seja alcançada, prazo que se estende para 217 anos quando se trata do quesito ambiente de trabalho, conforme apresenta a Figura 1.

Figura 1: Previsões de tempo para superar as diferenças entre gêneros.

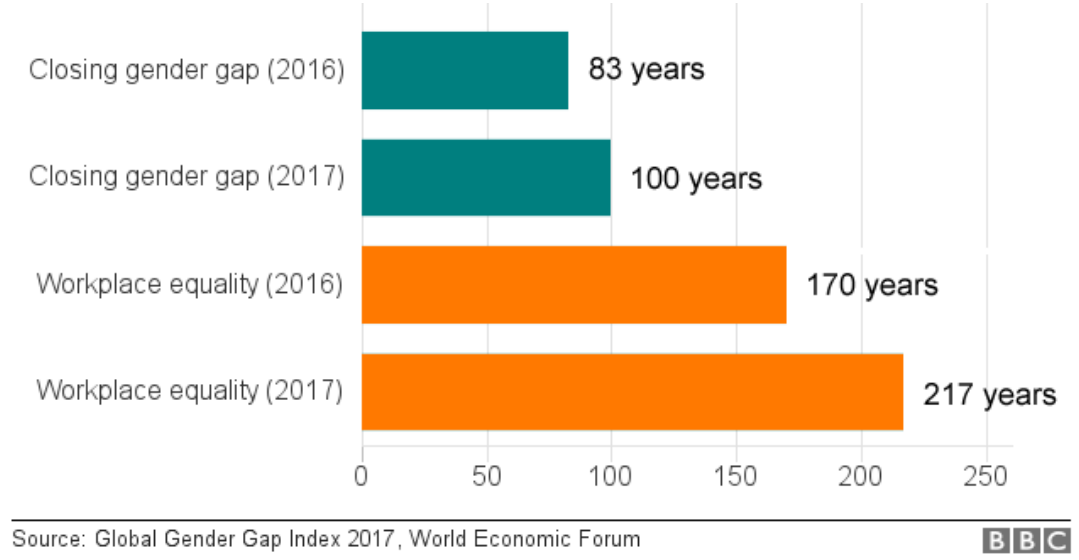

Fonte: BBC (2017).

A discrepância salarial, sobrecarga doméstica e parcialidade no ramo empregatício são alguns indícios da desigualdade de gêneros. É evidente que, na busca pela conquista dos direitos das mulheres, avanços já foram feitos, como é o exemplo dos estudos linguísticos, retratado no capítulo 17 do Handbook of Historical Sociolinguistic, intitulado "Class, Age, and Gender-based Patterns", escrito por Kiełkiewicz-Janowiak (2012). Nele, é apresentado uma discussão acerca de vários estudos de registros de textos escritos, considerando não os textos escritos por homens, mas dando ênfase aos textos escritos por mulheres de diversas origens sociais no final do século XVIII e início do XIX, na Nova Inglaterra.

Mesmo sendo uma inovação considerar textos femininos, a mulher no final do século XVIII e XIX, nos Estados Unidos, também era sub-representada, pois tinha a capacidade de ler, mas não de escrever. Seus textos eram muitas vezes privados (diários ou cartas), e por esta razão não eram publicados. Somado a isso, existia um grande 
desequilíbrio histórico entre os homens e mulheres, pois o homem era o marido e a mulher, a esposa responsável pela organização da casa e criação dos filhos.

Este avanço não impediu que em diversas esferas sociais a desigualdade de gênero ainda se faça presente. Buscar os papéis sociais atribuídos às mulheres nas diferentes sociedades e em diferentes períodos da história pode contribuir para a compreensão da emancipação feminina, a elevação de status social e a expressão dos ideais femininos.

Uma das formas de mostrar a importância das mulheres de uma sociedade, reconhecendo e eternizando seus feitos, seria através do registro de seus nomes e de suas histórias. Mas, quando se fala em toponímia, a importância dessas mulheres é retratada nos nomes dos logradouros? Os nomes femininos são escolhidos para denominar logradouros na mesma proporção dos nomes masculinos ou persiste a desigualdade de gênero? Essas perguntas cabem também no contexto de Araçuaí, município marcado pela força do seu povo, principalmente das mulheres, que tiveram papel fundamental na sua formação, e objeto deste estudo. Essas mulheres são reconhecidas através dos topônimos da cidade? E, por fim, as mulheres que são homenageadas através de nomes de logradouros tiveram papel social importante no município ou foram homenageadas por estarem ligadas a algum nome masculino de destaque para o município?

Estas foram algumas questões que se pretendeu pesquisar e apresentar neste estudo dos nomes de pessoas na toponímia de Araçuaí, que apresentará na sequência: os pressupostos teóricos que o subsidiaram, os procedimentos metodológicos utilizados, a apresentação e análise dos dados, algumas considerações e a bibliografia consultada.

\section{PRESSUPOSTOS TEÓRICOS}

\subsection{O ato de nomear e os nomes próprios}

Nomear é uma atividade que existe desde os primeiros tempos. No séc. IV a.C., o grande filósofo Platão, em seu diálogo Crátilo, já enxergava o ato de nomear muito além de um recurso para marcar a identidade. Em Platão (1973), Sócrates afirma que 
"nomear também é ação, uma vez que falar é uma espécie de ação, com relação a certas coisas" (PLATÃO, 1973, p.124).

Os nomes surgiram a fim de identificar objetos e situações. Com o passar do tempo, eles podem ser modificados ou não, uma vez que o léxico tende a acompanhar as mudanças socioeconômicas e/ou culturais de uma sociedade, conforme assegurado por Barros (2004). Ainda segundo Barros (2004: 26), "a cada nova invenção, a cada nova situação, atividade, produto, serviço, reivindicação, lei etc., surgiram novos termos correspondentes".

Sobre os nomes próprios, Jonasson (1994) afirma que constituem uma categoria linguística prototípica. Possuem propriedades típicas (introdução por maiúscula, flexão fixa, ausência de determinação em função referencial, falta de sentido lexical e designação de pessoas e lugares), mas não definitórias.

No que diz respeito aos nomes próprios de lugares, Dick (1990b), uma das mais conceituadas estudiosas da onomástica toponímica, ressalta que o topônimo, além de proporcionar ao homem um maior contato com o acidente nomeado, estabelece uma inegável relação de posse entre possuidor e objeto denominado. Por isso, a nomeação dos nomes próprios de lugares, que será abordada nas próximas seções, é uma prática exercida desde os primeiros tempos alcançados pela memória humana.

\subsection{Estudos Toponímicos}

A Toponímia, formada por topos (lugar) e onoma (nomes), é um componente da onomástica, que tradicionalmente buscava analisar a etimologia dos nomes de lugares, ditos nomes geográficos, e sua respectiva motivação, origem, evolução ou mudança através do tempo. Atualmente, busca também explicar os processos de constituição dos topônimos, assim como a motivação das escolhas e os aspectos linguísticos e socioculturais desses topônimos. Ou seja, "está voltada não apenas para análises etimológicas, mas léxico-semânticas de seu objeto de estudo, o topônimo" (DICK, 1990a, p. 1-10). Portanto, corroborando Heberle e Machado (2018), o topônimo não só identifica o lugar como também indica seus aspectos antropoculturais ou físicos.

Em 1901, com a obra de Theodoro Sampaio, Tupi na geografia nacional, iniciaram no Brasil os primeiros estudos toponímicos. Depois de 59 anos, Levy Cardoso 
escreveu Toponímia brasílica, em 1960. Nessa época, de acordo com Andrade (2010), a disciplina toponímia já fazia parte da grade curricular da Universidade de São Paulo (USP) desde 1944. No entanto, ainda eram poucos os estudos sobre topônimos e, quando feitos, não tinham um rigor metodológico.

Diante desse contexto, Dick (1990a) viu a necessidade de buscar modelos taxionômicos para um agrupamento macroestrutural dos topônimos. A autora fez algumas considerações na obra $O$ problema das taxeonomias toponímicas: uma contribuição metodológica, através da qual apresentou um quadro classificatório, utilizando as terminologias "elemento genérico" e "elemento específico". Em 1978, Dick propôs a primeira versão: uma taxionomia toponímica composta por dezenove taxes, com o intuito de preencher lacunas não contempladas na proposta de Stewart (1954), marcando assim uma nova fase para os estudos toponímicos no Brasil. Em 1986, na segunda versão, as taxes foram ampliadas para vinte e sete, agrupadas em duas categorias, a saber:

- Natureza física: motivação relacionada a aspectos naturais provenientes do meio ambiente, fauna, flora, mineral, acidentes geográficos etc. (1) Astrotopônimos; (2) Cardinotopônimos; (3) Cromotopônimos; (4) Dimensiotopônimos; (5) Fitotopônimos; (6) Geomorfotopônimos; Hidrotopônimos; (8) Litotopônimos; (9) Meteorotopônimos; Morfotopônimos; (11) Zoototopônimos.

- Natureza antropocultural: motivação relacionada aos aspectos culturais, religiosos, étnicos e históricos, como nomes próprios, de santos, povos indígenas etc. (1) Animotopônimos ${ }^{1}$ ou nootopônimos; (2) Antropotopônimos; (3) Axiotopônimos; (4) Corotopônimos; (5) Cronotopônimos; (6) Dirrematotopônimos; (7) Ecotopônimos; (8) Ergotopônimos; (9) Etnotopônimos; (10) Hierotopônimos (hagiotopônimos e mitotopônimos); (11) Historiotopônimos; (12) Hodotopônimos; (13) Numerotopônimos; (14) Poliotopônimos; (15) Sociotopônimos; (16) Somatotopônimos.

Apesar de ser uma proposta bem completa, Dick (1999) ressalta que: 
não são exaustivas em suas ocorrências e, sim, exemplificativas, podendo ser ampliadas em seus categoremas (fitotopônimos, ergotopônimos, somatotopônimos, etc.) à medida que novas estruturas vocabulares se constituam, respeitando sempre o modelo originário, assim descrito: adoção de um prefixo nuclear (greco-latino) de característica nocional, relativo a um dos dois campos de ordenamento cósmico, o físico e o humano; acréscimo do termo "topônimo" ao elemento prefixal, para dar a justa medida do campo de atuação da unidade onomástica criada. (DICK 1999, p. 142)

Assim, a autora sugere que, à medida que haja o surgimento da necessidade comprovada por pesquisas sobre os topônimos, novas taxes podem e devem ser acrescentadas, desde que respeitados os critérios apresentados. Dick (1999) deixa claro, dessa forma, que o acréscimo de taxes não pode ocorrer de forma aleatória.

A partir dos estudos de Dick, Seabra, Isquerdo e Castro, outros estudos toponímicos têm se destacado no Brasil nas últimas décadas, principalmente através dos atlas toponímicos, que têm por objetivo reconhecer a toponímia do país sob os pontos de vista lexical, etimológico, morfossemântico e etnolinguístico, levando os pesquisadores à percepção dos motivos socioculturais predominantes na onomástica brasileira, através das designações.

Dentre os Atlas desenvolvidos no cenário brasileiro, é possível citar: o Atlas Toponímico do Brasil (ATB), desenvolvido na USP, sob a coordenação da professora Dra. Maria Vicentina de Paula do Amaral Dick; o Atlas Toponímico do Estado de Minas Gerais (ATEMIG), desenvolvido na Universidade Federal de Minas Gerais (UFMG) e coordenado pela toponimista professora Dra. Maria Cândida Trindade Costa de Seabra; o Atlas Toponímico do Estado do Maranhão (ATEMA) que, assim como o Atlas Toponímico do Estado do Mato Grosso do Sul (ATEMS), é supervisionado pela professora Dra. Aparecida Negri Isquerdo, da Universidade Federal do Mato Grosso do Sul (UFMS), dentre outros.

Foram analisados os antropônimos, nomes de pessoas, que evoluíram para antropotopônimos, nomes de pessoas utilizados para nomear lugares. São nomes que não foram escolhidos pela comunidade, mas determinados e impostos pelo legislativo ${ }^{2} \mathrm{e}$ executivo. Essa forma de nomeação toponímica baseada em documentos oficiais ou atos fundacionais é defendida por Solis Fonseca (1997). Ela ocorre quando, por exemplo, o chefe do executivo escolhe determinada personalidade para ser homenageada e atribui seu nome a um logradouro. Essa situação dificulta a análise sociocultural deste nome, tendo em vista a necessidade de um estudo mais aprofundado que considere a história e 
a transformação desse topônimo no decorrer do tempo, bem como o contexto que originou sua criação e que justifica seu uso.

Na sequência, são apresentados os procedimentos metodológicos utilizados para o desenvolvimento deste estudo, que analisou a ocorrência dos nomes e/ou apelidos de mulheres, seguidos ou não de títulos, nos nomes dos logradouros urbanos da cidade de Araçuaí-MG.

\section{PROCEDIMENTOS METODOLÓGICOS}

Nesta seção faz-se uma breve apresentação do município de Araçuaí, objeto desta pesquisa e na sequência quais foram os procedimentos metodológicos utilizados para a realização do estudo.

\subsection{Caracterização do município pesquisado: Araçuaí}

(Calhau< Vila Arassuay< Arassuahy< Arassuaí< Araçuaí)

Gentílico: araçuaiense.

Araçuaí é um município localizado no nordeste de Minas Gerais, mais especificamente no Médio Jequitinhonha, a $678 \mathrm{~km}$ de distância da capital Belo Horizonte. É formado pela sede e pelos distritos de Engenheiro Schnoor e Itira, além de, aproximadamente, 67 comunidades rurais. De acordo com dados do IBGE de 2010, a população total é de 36.013 habitantes. Sua emancipação política ocorreu no dia 21 de setembro de 1871 , por força da Lei $n^{\circ} 1870$. Inicialmente, Calhau ${ }^{3}$ era o nome do arraial que nos anos de 1830 começou a se formar entre a chapada do Piauí e a do Candonga.

Embora a tradição oral insista em dizer que o município de Araçuaí foi fundado por uma prostituta de nomes Luciana Teixeira, optou-se, neste trabalho por considerar o que é documentado através de textos de August Saint-Hilaire (1975) e Leopoldo Pereira (1969), que assim escrevem

\footnotetext{
...Padre Carlos era excessivamente autoritário e exigente. Lançando os fundamentos de uma futura cidade, portou-se como senhor de alta e baixa justiça, e uma de suas determinações foi que não se consentissem ali meretrizes nem bebidas alcoólicas. As infelizes mulheres emigraram, e,
} 
atraídos por elas os canoeiros mudaram de porto. Nesse tempo era proprietária da Fazenda Boa-Vista do Calhau uma velha mulata de nome Luciana Teixeira... essa boa mulher deu abrigo aos emigrantes do Pontal em suas terras... (PEREIRA, 1969, p. 91-92)

Portanto Luciana Teixeira, uma mulher caridosa, era proprietária da Fazenda Boa Vista e desafiando a tudo e todos, acolheu em suas terras as mulheres que vieram da Barra do Pontal expulsas pelo Padre Moura, que seguia os dogmas religiosos. Consequentemente, os canoeiros também passaram a se aportar neste local, dando origem às primeiras construções. Essa versão é a que mais condiz com os relatos de viagens de Auguste de Saint-Hilaire (1975), que assim descreve a fazenda Boa Vista, propriedade de Luciana Teixeira

Boa Vista era a residência de uma velha mulata chamada Luciana Teixeira. Tendo sabido que eu viajava com passaporte do governo, essa boa mulher cumulou-me de atenções, e, pondo-se quase de joelhos, quis abraçar-me as coxas; mas compreende-se bem que recusei a semelhante polidez. (SAINTHILAIRE, 1975, p. 238)

Em outro trecho, o autor se manifesta sobre Luciana Teixeira da seguinte maneira:

\footnotetext{
Passei em Boa Vista o dia de Pentecostes. Um sacerdote ali chegara, vindo de nove léguas de distância, e todos os colonos da vizinhança se tinham reunido na habitação com os filhos e netos de minha hospedeira, para assistir ao serviço divino. Essa boa gente jantou em casa dela: a mesma mesa foi posta e desfeita várias vezes, e os que, depois disso, acharam não ter comido bastante, jantaram, depois confusamente. (SAINT-HILAIRE, 1975, p. 238)
}

Em nenhum momento ele faz parecer que se tratava de uma prostituta. Pelo contrário, ele diz que a hospedeira sequer cobrou algo pela hospedagem e pelas refeições, pedindo a ele apenas papéis. Assim, é possível deduzir que não se tratava de uma pessoa gananciosa. O trecho acima também permite inferir ser injustiça a atribuição à Luciana do título de prostituta, uma vez que mostra que era uma senhora de idade já em 1817. Portanto, em 1830, época de fundação do arraial, deveria estar bem idosa. Além disso, parece que sua casa era um local onde as pessoas gostavam de estar, inclusive para eventos religiosos, conforme descrito acima.

Essa contextualização demonstra que, desde antes de sua fundação, a participação feminina teve grande importância na formação de Araçuaí. Segundo 
Pereira (1969) e Saint-Hilaire (1975), nessa época, Luciana Teixeira, proprietária da Fazenda da Boa Vista na Barra do Calhau, abrigou em suas terras, à margem direita do ribeirão do Calhau e de Araçuaí, os emigrantes do Pontal, principalmente mulheres, de forma que o local se tornou ponto de arribada das canoas que subiam o Jequitinhonha.

De acordo com Sampaio (1987) e Costa (1970), o nome Araçuaí é um topônimo originado do tupi Araçoyá-y, que significa rio do chapéu ou do cocar, o que faz sentido porque, na época, a região era habitada por povos indígenas, apesar de existirem versões populares com as seguintes explicações para o surgimento do nome

"... na iscola falava né... que era Luciana Teixeira né que discubriu Araçuaí né... e porque... que na... tinha muita lavra, o rio também dava muito diamante e ouro é, e ela falou que... quando ela orientava o garimpeiro aí ela falava: nesse local aí "oro só aí" falava assim "oro só aí", por causa do ôro só aí que surgiu Araçuaí"...4

"... deram o nome de Araçuaí porque na época, naquela época da dona Luciana Teixeira o único meio de transporte que aqui tinha era canoa, canoa e o lombo de burro né. Depois que foi emancipada é... recebeu o nome de Araçuaí porque... na região aqui havia muita arara então o pessoal falava "arara só aí, arara só aí", e resolveram falar Araçuaí"...5

A partir dos relatos acima, é possível inferir que informações históricas e socioculturais de um povo podem ser resgatadas por gerações futuras por meio da motivação toponímica real ou histórias do imaginário das pessoas do lugar nomeado.

Araçuaí é cidade polo do Médio Jequitinhonha. Porém, todo o Vale do Jequitinhonha é caracterizado pelo aspecto contrastante da sua realidade: de um lado, a riqueza destacada pelas potencialidades do subsolo, promissor em recursos minerais, grande patrimônio histórico e cultural, referência para Minas Gerais e para o Brasil por seu artesanato diversificado e seus múltiplos atrativos turísticos; de outro lado, a extrema pobreza em que vive grande parte de sua população.

\subsection{Procedimentos metodológicos}

Foi feito um recorte dos logradouros com nomes de pessoas na cidade de Araçuaí, ou seja, 174 antropotopônimos coletados a partir de mapas, relatórios, decretos, leis e outros documentos públicos do município. No Quadro 1 a seguir, são elencados todos os dados encontrados: 
Quadro 1: Antropotopônimos de Araçuaí-MG

\begin{tabular}{|c|c|}
\hline $\begin{array}{l}\text { 1. Adilson Santana Campos } \\
\text { 2. Afonso Pena } \\
\text { 3. Airton Sena } \\
\text { 4. Alexandrino Pereira } \\
\text { 5. Alfredo Almeida } \\
\text { 6. Alfredo Graça } \\
\text { 7. Amaro José do Carmo } \\
\text { 8. Angel Pereira } \\
\text { 9. Antero Pereira } \\
\text { 10. Antônio Bragança } \\
\text { 11. Antônio Cachiado } \\
\text { 12. Antônio Carlos Magalhães } \\
\text { 13. Antônio Cláudio de Carvalho } \\
\text { 14. Antônio Cosenza Leite } \\
\text { 15. Antônio de Matozinhos Neiva } \\
\text { 16. Antônio Hermano Martins } \\
\text { 17. Antônio Tanure } \\
\text { 18. Aristides Brandão } \\
\text { 19. Arnaldo Gonçalves Dibai } \\
\text { 20. Arnaldo Peixoto } \\
\text { 21. Arthur Berganholi } \\
\text { 22. Asdrúbal da Cunha Melo } \\
\text { 23. Augusto da Costa Pereira } \\
\text { 24. Aurora Teles } \\
\text { 25. Belizário Fulgêncio } \\
\text { 26. Benjamim Constant } \\
\text { 27. Bernardo Teixeira } \\
\text { 28. Canoeiro José Alves de Carvalho } \\
\text { 29. Cantídio Amaral } \\
\text { 30. Celso José Carmona } \\
\text { 31. Chico Anísio } \\
\text { 32. Clemente Santana } \\
\text { 33. Clementino Silveira } \\
\text { 34. Coronel Inácio Murta } \\
\text { 35. Coronel José Antônio Tanure } \\
\text { 36. Costa Sena } \\
\text { 37. Danilo Fulgêncio } \\
\text { 38. Dionízio Rodrigues de Oliveira } \\
\text { 39. Dom José de Haas } \\
\text { 40. Dom Serafim } \\
\text { 41. Dona Hebe Colares } \\
\text { 42. Dona Quiqui } \\
\text { 43. Dr. Armando Mesquita } \\
\text { 44. Dr. Nuno Melo } \\
\text { 45. Dr. Túlio Hostílio } \\
\text { 46. Dr. Walter Diniz Camargos } \\
\text { 47. Duque de Caxias } \\
\text { 48. Edith da Cunha Melo } \\
\text { 49. José Onnis Chiesa } \\
\text { 50. José Pinto Colares } \\
\text { al }\end{array}$ & 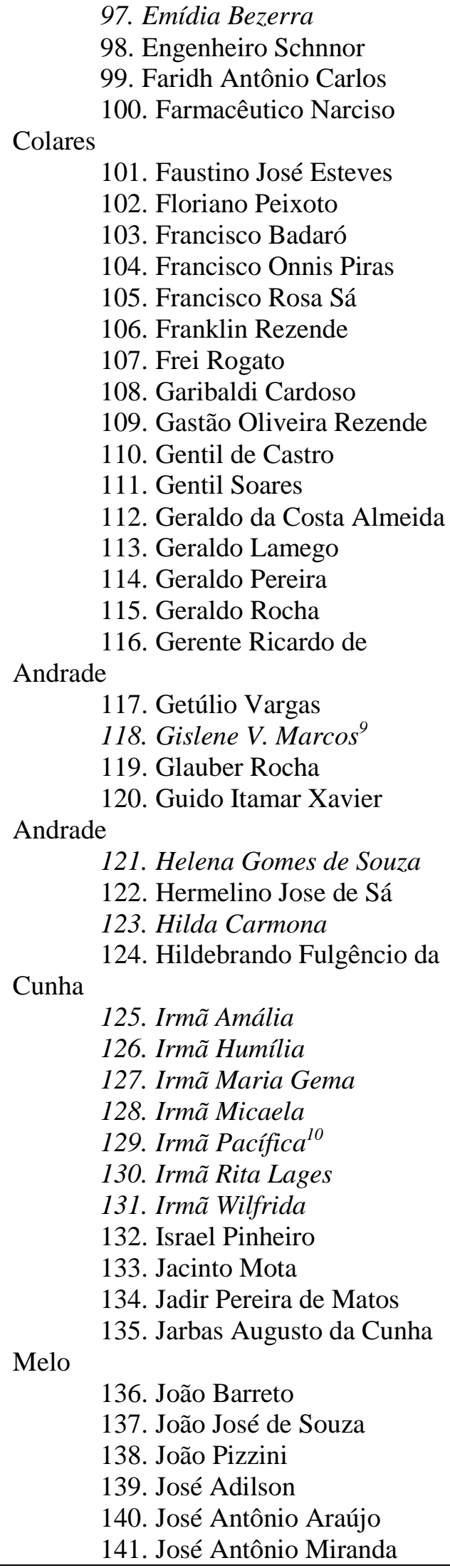 \\
\hline
\end{tabular}




\begin{tabular}{|c|c|}
\hline $\begin{array}{l}\text { 51. José Tanure } \\
\text { 52. José Tanure Neto } \\
\text { 53. Jovino Pereira } \\
\text { 54. Juca Campos } \\
\text { 55. Judith Pinheiro Lopes } \\
\text { 56. Juiz de Paz Jaime Cunha Melo } \\
\text { 57. Juiz de Paz Pedro Carvalho } \\
\text { 58. Juventino Ferreira } \\
\text { 59. Leda Peixoto } \\
\text { 60. Leonel Brizola } \\
\text { 61. Leonice Jardim } \\
\text { 62. Leonidas Fulgêncio } \\
\text { 63. Letâncio Murta } \\
\text { 64. Luciana Teixeira } \\
\text { 65. Luiz Gonzaga Pereira } \\
\text { 66. Manoel Fulgêncio } \\
\text { 67. Manoel Gusmão } \\
\text { 68. Marconi Pereira } \\
\text { 69. Marechal Deodoro } \\
\text { 70. Maria A. Colares Sáb } \\
\text { 71. Prof. }{ }^{a} \text { Maria de Consenza Leite } \\
\text { 72. Prof } M^{a} \text { Miranda Cunha } \\
\text { 73. Marial Humberto Timo } \\
\text { 74. Mário Chaves } \\
\text { 75. Miguel Arraes } \\
\text { 76. Miguel Chalub } \\
\text { 77. Millôr Fernandes } \\
\text { 78. Monsenhor Clóvis da Fonseca } \\
\text { 79. Mozart José de Souza } \\
\text { 80. Nagib Zaiter Tanure } \\
\text { 81. Narciso Vieira } \\
\text { 82. Nilson Barbosa de Andrade } \\
\text { 83. Odília Moreira } \\
\text { 84. Odílio Vieira Santos } \\
\text { 85. Ofélia Fulgêncio } \\
\text { 86. Olegário Maciel } \\
\text { 87. Osório Colares } \\
\text { 88. Otacílio Martins } \\
\text { 89. Padre João Antônio Pinheiro } \\
\text { 90. Pedro Celestino } \\
\text { 91. Pedro da Costa Almeida } \\
\text { 92. Pedro Espínola da Silva } \\
\text { 93. Pedro Gonçalves Santos } \\
\text { 94. Prefeito Franklin Fulgêncio } \\
\text { 95aria Gomes } \\
\text { Trof. Leopolo Pereira } \\
\end{array}$ & 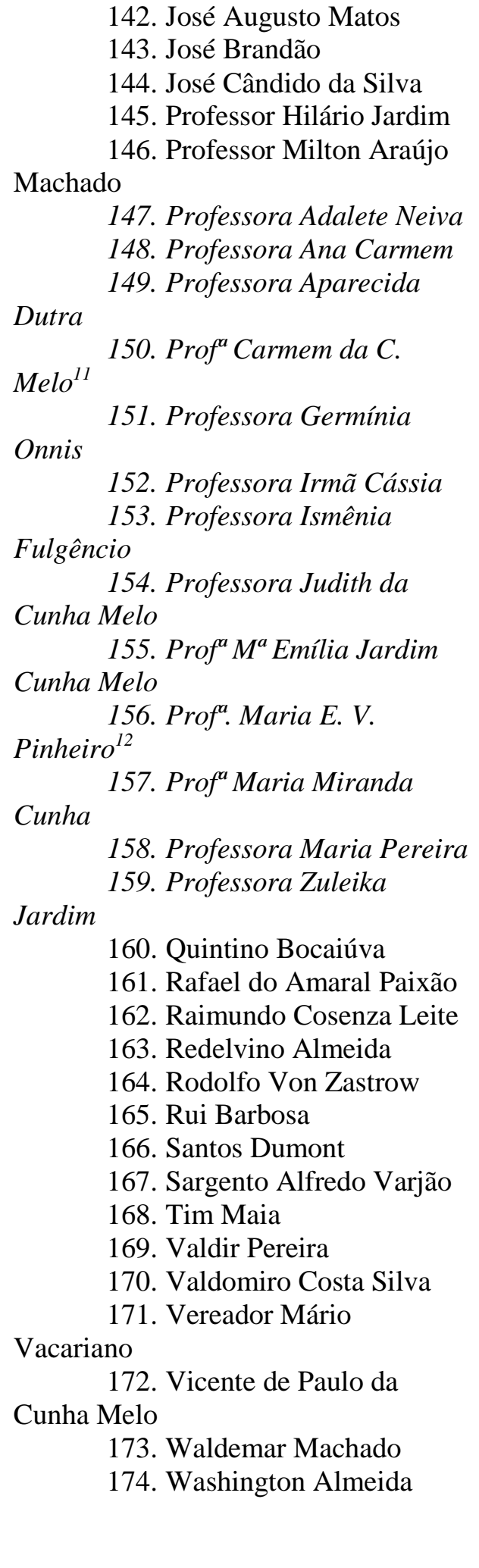 \\
\hline
\end{tabular}

Após o levantamento de todos os antropotopônimos, procedeu-se à seleção dos nomes femininos, de interesse deste trabalho, conforme o Quadro 2 abaixo: 
Quadro 2: Nomes femininos nos logradouros de Araçuaí-MG

\begin{tabular}{|c|}
\hline Nome do Logradouro \\
\hline 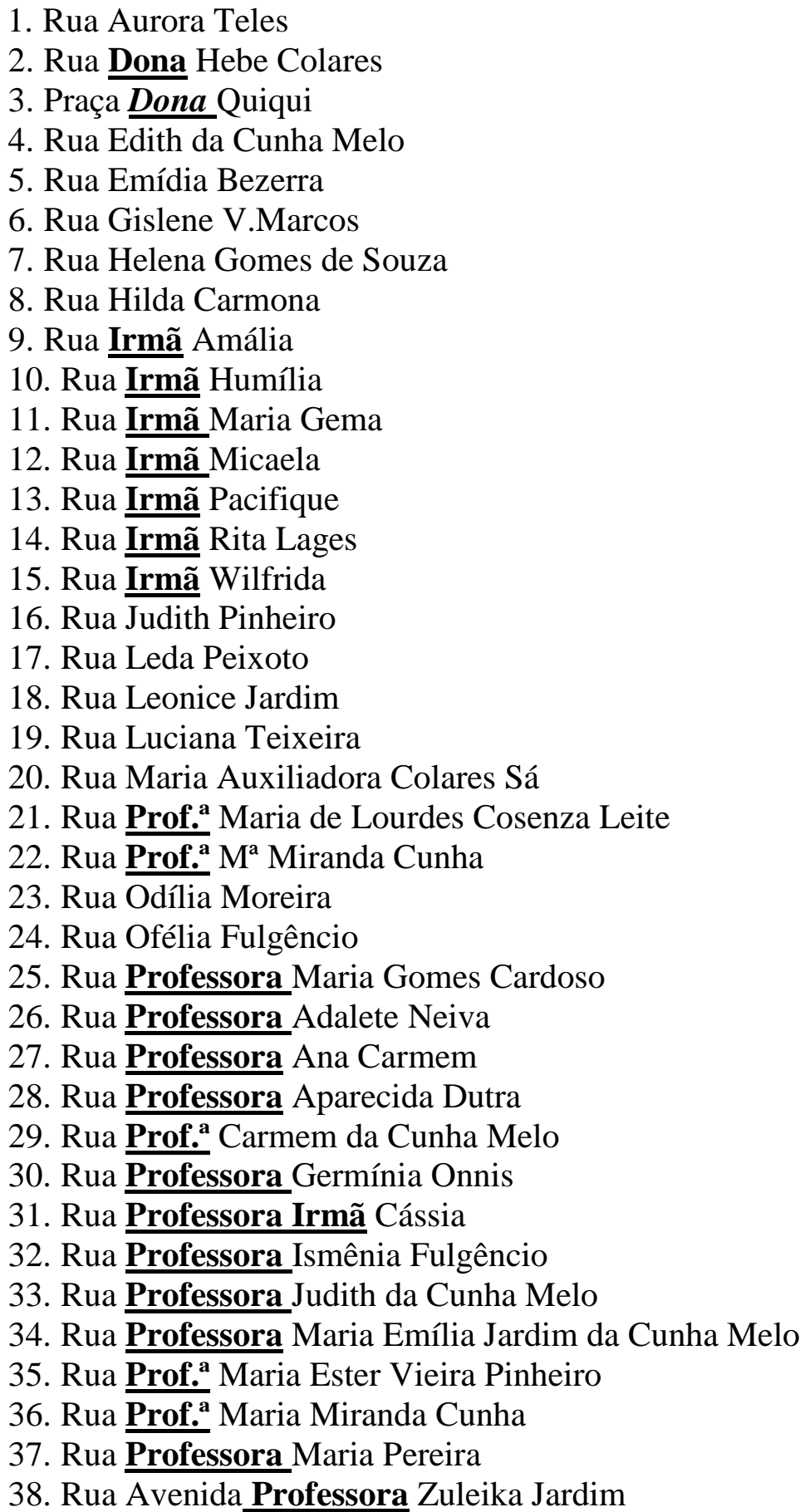 \\
\hline
\end{tabular}

Selecionados os nomes femininos, procurou-se investigar quem eram as mulheres homenageadas, quais papéis sociais exerciam no município ou se possuíam algum vínculo familiar com o ex-coronel ${ }^{13}$ do município ou alguma figura relevante 
para a região. Para a investigação, foram consultados documentos da biblioteca pública municipal, livros de autores da região, acervos da prefeitura, além de coletas orais com pessoas da cidade a fim de obter informações sobre as homenageadas e suas atividades.

Sobre a classificação toponímica dos nomes de lugares com nomes de pessoas, Dick (1990b) os divide em 03 grupos: antropotopônimos (logradouros com nomes de pessoas), axiotopônimos (logradouros com nomes de pessoas acompanhados de um título) e historiotopônimos (logradouros com nomes de pessoas que fizeram parte de movimento histórico e cultural no país). Neste estudo, porém, optou-se por utilizar uma nova proposta feita por Faria (2017), na qual a autora classifica todos os logradouros com nomes de pessoas primeiramente como antropotopônimos e depois os subdivide em axiotopônimos e historiotopônimos, ficando assim:

a) Antropotopônimos: nomes de pessoas sem acompanhamento de título. Ex: Rua Narciso Vieira;

b) Antropo-axiotopônimos: nomes de pessoas acompanhados de títulos. Ex: Rua Professor Hilário;

c) Antropo-historiotopônimos: nomes de pessoas que foram importantes para a história do país. Ex: Praça Getúlio Vargas;

d) Antropo-axio-historiotopônimos: nomes de pessoas que foram importantes para a história do país, seguido de título. Ex: Praça Presidente Getúlio Vargas.

\section{APRESENTAÇÃO DOS DADOS, ANÁLISE E RESULTADOS}

Os dados coletados chamaram a atenção pela diferença entre o quantitativo de nomes masculinos (136) e nomes femininos (38) atribuídos a logradouros da cidade, conforme o Quadro 1, demonstrado abaixo no

Gráfico 1. Verificou-se, então, que semelhante ao que acontece em outras esferas como a política, por exemplo, no que se refere a gênero, em Araçuaí existe um grande descompasso entre o quantitativo de nomes masculinos e femininos na toponímia, mesmo sabendo que diversas mulheres, no anonimato de suas profissões, contribuíram significativamente para o desenvolvimento do município. 
Gráfico 1: Distribuição dos antropotopônimos de Araçuaí por gênero.

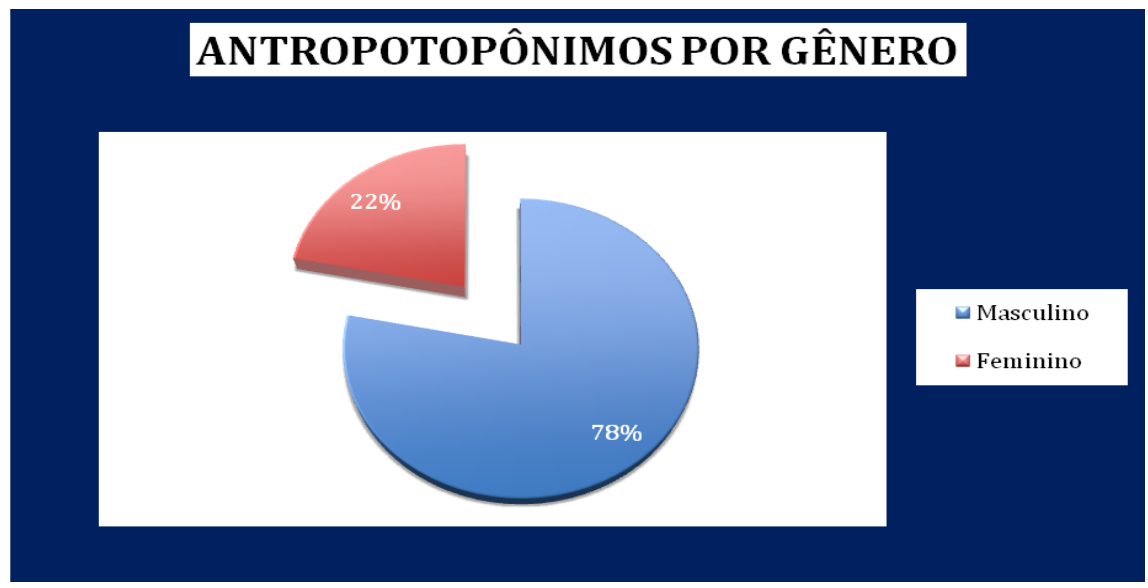

Embora se atribua a uma mulher o início da formação de Araçuaí, os primeiros antropônimos utilizados como nomes de logradouros não foram de Luciana Teixeira ou qualquer outra mulher. A rua mais antiga de Araçuaí tem o nome de Gentil de Castro, anteriormente chamada Rua de Baixo, enquanto a praça mais antiga se chama Praça Getúlio Vargas. Conforme os indícios, prevalecem os nomes masculinos nos logradouros da cidade, como constatado neste trabalho, ratificando a desigualdade de gênero também na toponímia.

Seguindo a classificação proposta por Faria (2017), os logradouros com nomes de mulheres em Araçuaí, em relação à classificação toponímica, apresentaram a seguinte configuração:

Gráfico 2: Classificação toponímica dos logradouros com nomes femininos.

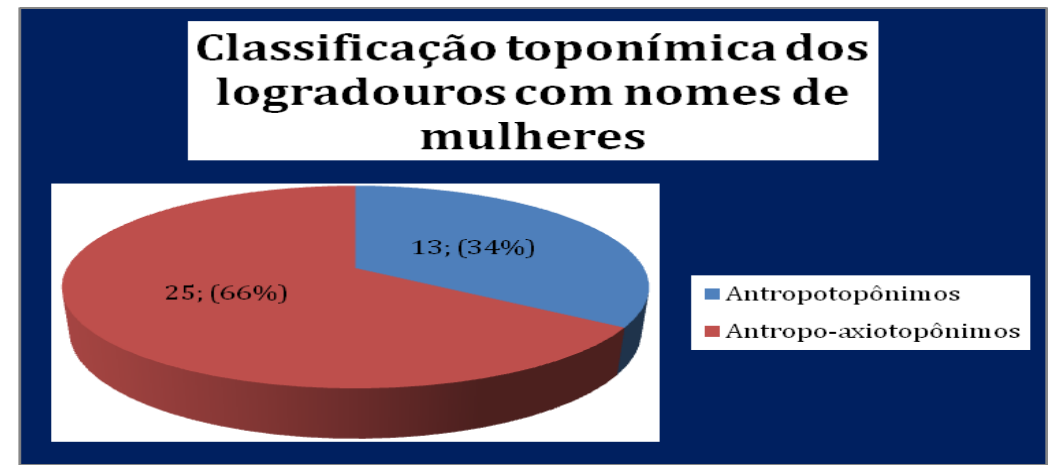

Dos 38 nomes de mulheres, conforme o Quadro 2, 25 (vinte e cinco) nomes aparecem seguidos de títulos (antropo-axiotopônimos) e 13 (treze) não são acompanhados por títulos (antropotopônimos). Mesmo não aparecendo o título na 
denominação dos logradouros, todas as homenageadas tiveram um papel social relevante na cidade, conforme detalhado no quadro abaixo:

Quadro 3: Papel social das mulheres homenageadas em Araçuaí

\begin{tabular}{|c|c|c|}
\hline Quantitativo & Função & Nomes \\
\hline 24 & $\begin{array}{l}\text { Professoras/diretoras de } \\
\text { escola }\end{array}$ & $\begin{array}{l}\text { Dona Quiqui, Edith da Cunha Melo, Emídia } \\
\text { Bezerra, Gislene Vieira Marcos, Maria } \\
\text { Auxiliadora Colares Sá, Maria de Lourdes } \\
\text { Cosenza Leite, Maria Miranda Cunha, Ofélia } \\
\text { Fulgêncio, Maria Gomes Cardoso, Adalete } \\
\text { Neiva, Ana Carmem, Aparecida Dutra, Carmem } \\
\text { da Cunha Melo, Germínia Onnis, Hebe Colares, } \\
\text { Ismênia Fulgêncio, Judith da Cunha Melo, Judith } \\
\text { Pinheiro, Leonice Jardim, Maria Emília Jardim } \\
\text { da Cunha Melo, Maria Ester Vieira Pinheiro, } \\
\text { Maria Miranda Cunha, Maria Pereira, Zuleika } \\
\text { Jardim. }\end{array}$ \\
\hline 08 & Freiras $^{14}$ & $\begin{array}{l}\text { Amália, Cássia }{ }^{15} \text {, Humília, Maria Gema, Micaela, } \\
\text { Pacifique, Rita Lages, Wilfrida. }\end{array}$ \\
\hline 02 & Comerciantes & $\begin{array}{l}\text { Aurora Teles (dona de pensão), Leda Peixoto } \\
\text { (dona de cartório) }\end{array}$ \\
\hline 02 & Ex-funcionárias públicas & $\begin{array}{l}\text { Hilda Carmona (ex-funcionária pública, primeira } \\
\text { mulher de Araçuá a fazer o título eleitoral), } \\
\text { Odília Moreira (ex-funcionária do DER } \\
\text { Departamento de Estradas e Rodagens). }\end{array}$ \\
\hline 01 & Fazendeira & $\begin{array}{l}\text { Luciana Teixeira, a primeira figura feminina do } \\
\text { município de extrema importância para Araçuaí, } \\
\text { a quem é atribuída a fundação da cidade. }\end{array}$ \\
\hline 01 & Liderança popular & $\begin{array}{l}\text { Helena Gomes de Souza (Uma das fundadoras do } \\
\text { Partido dos Trabalhadores em Araçuaí, liderança } \\
\text { popular). }\end{array}$ \\
\hline
\end{tabular}

A maioria das homenageadas (24) foram ex-professoras e/ou diretoras de escolas, cujo título de professora apresenta variação na grafia, escrito ora abreviado ora por extenso, seguido dos nomes. Apesar de muitas das homenageadas possuírem parentesco com alguma figura masculina relevante para Araçuaí, o destaque se dá pelo papel fundamental que desempenharam, principalmente na educação do município. Dona Ofélia Fulgência, por exemplo, esteve à frente da Escola Manoel Fulgêncio por 40 anos e todas as citadas acima foram de suma importância para o município. Entretanto, muitas outras que mereciam ser homenageadas permanecem no anonimato.

Na sequência, apareceu o título de irmã (08) se referindo às freiras, muitas, também, ex-professoras do Colégio Nazareth, porém apenas no logradouro com o nome da Irmã Cássia são citados os dois títulos: Rua Professora Irmã Cássia, confirmando a 
forte ligação entre educação e religiosidade no município. De acordo com Botelho (2007), em 1926, seis freiras voluntárias, Irmã Amália ${ }^{16}$, Irmã Boa Vida, Irmã Angélica, Irmã Guilhermina, Irmã Beatriz e Irmã Aquilina, da Congregação Franciscana OirschotHolanda, vieram para Araçuaí a pedido dos bispos Dom Serafim e Dom José de Haas para fundar um colégio feminino. As freiras saíram da Holanda de navio e, depois de 18 dias, em 10 de março de 1926, chegaram ao Rio de Janeiro. Continuaram de navio costeiro até Caravelas. Depois, de trem, foram para Teófilo Otoni e posteriormente para Queixada. Então, finalmente partiram para Araçuaí, montadas em cavalos pela primeira vez, percorrendo muitas léguas. Depois de 43 dias chegaram ao município, onde foram recepcionadas festivamente e no dia 23 de abril de 1926, deram início às atividades do colégio Nazareth.

Das oito freiras e ex-professoras do Colégio Nazareth que foram homenageadas com topônimos, cinco eram holandesas (Amália, Humília, Micaela, Pacifique ${ }^{17}$ e Wilfrida) e três eram brasileiras (Maria Gema, Rita Lages e Cássia), sendo a Irmã Rita Lages a única filha de Araçuaí. É importante ressaltar que os nomes religiosos pelos quais eram conhecidas não eram os seus nomes civis, de forma que a Irmã Maria Gema tinha como nome de batismo Cinira Lorentz, Irmã Rita Lages, o nome de Olímpia Augusta Guedes e Irmã Cássia tinha o nome civil de Maria do Carmo Tavares. Conforme Botelho (2007)

Irmã Pacifique chegou a Araçuaí em 1967, para trabalhar no Colégio Nazareth. Logo, ela se compadeceu dos idosos e mendigos abandonados na rua. Procurou ajuda e abrigo para essa gente. O resultado é que se desligou do Colégio Nazareth, dedicando-se totalmente àquilo que foi o início desta obra social. (BOTELHO, 2007, p.64)

Irmã Pacifique foi uma figura feminina de destaque na área social, principalmente sendo responsável por, juntamente com a igreja católica, adquirir um terreno e construir a Ação Social Santo Antônio, uma Entidade Filantrópica que durante 47 anos acolheu idosos e crianças abandonados e/ou em situação de risco social, passando a partir de 2017 a acolher somente idosos.

Também, nos nomes dos logradouros, apareceram registrados duas vezes a forma de tratamento dona como título: Dona Quiqui ${ }^{18}$ (Maria Joaquina da Cunha Melo) e Dona Hebe Colares, duas ex-professoras muito respeitadas e queridas na cidade. Dona 
Quiqui além de ser ex-professora de Educação Moral e Cívica, tocava piano, era ministra da eucaristia e dona de cartório.

Sobre o antropotopônimo Luciana Teixeira, uma das figuras femininas mais importantes para Araçuaí, Santos (2012) assim escreve

No caso de Luciana Teixeira, ao se ousar romper uma postura machista no final do século XIX, pouco lhe restou de reconhecimento na emancipação e desenvolvimento do município. Hoje, no município, vamos encontrar uma pequena rua sem saneamento básico de casas populares que leva o seu nome. (SANTOS, 2012, p.14-15)

O pouco reconhecimento da importância de Luciana Teixeira para o município, mesmo sendo contado e recontado que seria a fundadora da cidade, se deve, possivelmente, à dúvida que se espalhou sobre sua índole que, corroborando Santos (2012), são apenas indícios de preconceitos da época devido ao fato de ela ter acolhido em suas terras prostitutas expulsas de outro local por um padre. Este comportamento discriminatório imposto pelos padrões estabelecidos na época se espalhou ao longo dos anos deixando marcas e julgamentos no imaginário popular.

Mesmo com mulheres tão importantes para a história da cidade, constatou-se através dos dados que prevalecem os nomes masculinos em detrimento dos femininos nos nomes de logradouros do município de Araçuaí, demonstrando uma desigualdade de gênero na toponímia de Araçuaí, cidade pertencente a uma região onde as mulheres sempre se fizeram presentes, desde quando Luciana Teixeira acolheu mulheres expulsas da Barra do Pontal em suas Terras.

Outro aspecto importante observado é que mesmo Araçuaí, assim como todo o Vale do Jequitinhonha, sendo uma região com várias riquezas culturais, com expressivo número de artistas, poetas, artesãos, parteiras e benzedeiras não foi encontrado nenhum logradouro com nome de benzedeira, artesã etc. Além de Luciana que desbravou matas, diversas mulheres deram o melhor de si para o lugar como as ilustres Madre Lúcia, Irmã Inês que prestaram relevantes serviços ao Hospital São Vicente de Paula, enfermeiras e diretoras do hospital, passando noite cuidando de doentes (SANTOS, 2012). Temos ainda Sá Luiza, mulher de fé, que cuidava da dor de muita gente, Maria da Conceição Soares Almeida, primeira vereadora entre 1983-1986 e tantas outras mulheres importantes para o município, mas invisíveis na toponímia araçuaiense. 
Alternativamente, pode-se constatar que cargos considerados de prestígio para a cidade, como o de médico, advogado, dentista, entre outros, eram destinados a homens, de maneira que a maioria das mulheres que não eram donas de casas ocupava a função de professora, que também não era acessível a todas as mulheres. Essa questão fica explícita no registro dos nomes dos logradouros e ratifica a importância e influência da mulher na educação.

Importância ratificada ao constatar que das 38 mulheres homenageadas pelos topônimos, 24 são mulheres que exerceram um papel de extrema relevância na educação do município como professora e/ou diretora de escola, embora ainda falte homenagear tantas outras professoras que fazem parte da história do município. A professora Edith da Cunha Melo, por exemplo, era filha do médico Nuno Cunha Melo, que foi uma figura de destaque em Araçuaí, conhecido por ser uma pessoa extremamente acolhedora e caridosa, que saía a cavalo para visitar seus pacientes. No entanto, não foi por este motivo que se destacou, mas sim por ser responsável por ensinar português aos padres franciscanos holandeses que chegaram à cidade, além de usar o casarão da família como escola para ensinar moças pobres da zona rural, conforme dados do arquivo de tombamento do Casarão da Família Cunha Melo.

Outra mulher homenageada foi Dona Helena Gomes de Souza, também conhecida como Helena do Cocão, Helena do Arraial, Helena do Sô Tião das bananas ou ainda Helena do PT. Filha de franceses da família Bitencourt, remanescente do quilombo, dona de casa, mãe de 16 filhos, que só estudou até a $4^{\text {a }}$ série por falta de condições financeiras, mas foi uma pessoa de muita importância pela sua característica de mulher forte, destemida, líder comunitária do bairro Arraial dos Crioulos e muito bem quista pelas pessoas. Segundo informações coletadas com sua filha, também de nome Helena, ela exercia o papel de enfermeira, psicóloga, mãe, avó, benzedeira e sempre estava disposta a ajudar a todas as pessoas que precisavam. Importante ressaltar que Dona Helena foi uma das lutadoras pelo partido dos trabalhadores em Araçuaí, o que a fez sofrer muitas perseguições. Ela foi a primeira mulher candidata a vereadora pelo Partido dos Trabalhadores, o que é um dado importante, tendo em vista o contexto político do município extremamente masculino. Em 25 mandatos de prefeito apenas 1 (um) foi exercido por uma mulher, Maria do Carmo Ferreira da Silva, no período de 1997 a 2000. 
Por fim, pretende-se em um próximo trabalho, apresentar a biografia de todas estas mulheres que tiveram seus nomes lembrados no ato de nomeação dos logradouros de Araçuaí e mostrar que, mesmo em número bem inferior ao dos nomes masculino, se mostraram essenciais para o município, principalmente na esfera educacional.

\section{CONSIDERAÇÕES FINAIS}

O topônimo tem uma intrínseca relação com a memória de um povo, mesmo quando o povo se esquece da motivação toponímica. Muitas vezes, essa motivação se torna opaca no decorrer do tempo por fatores como, por exemplo, a extinção de uma cultura e/ou uma língua. Por isso, é importante que seja feita uma consulta à população antes de se atribuir o nome de uma pessoa a algum logradouro, de forma que a decisão não seja apenas do legislativo ou do dono de loteamento.

Mesmo sendo uma cidade com personalidades femininas fortes, que muitas vezes já foram chamadas de "viúvas de marido vivo" por assumirem as rédeas da casa, enquanto os maridos buscavam o sustento da família no corte de cana ou na colheita de café em outros estados, essas figuras, ainda que não tenham se mostrado invisíveis na toponímia, se tornam pouco visíveis. Feita uma análise quantitativa, verificou-se que dos 174 nomes de pessoas na toponímia urbana de Araçuaí, apenas 38, equivalente a $22 \%$, foram nomes femininos, ao passo que 136 , ou seja, $78 \%$ dos logradouros tiveram nomes masculinos.

Por outro lado, não restam dúvidas de que as 38 mulheres homenageadas pelos topônimos foram de extrema relevância para o município, assim como várias outras figuras femininas que fizeram história em Araçuaí e ainda não apareceram nos topônimos. Pode-se afirmar que os nomes dos logradouros públicos ratificaram a pouca visibilidade da figura feminina na toponímia de Araçuaí. Algumas hipóteses levantadas e que sugerem um estudo mais aprofundado sobre o tema e em regiões diferentes do país são: (1) o desconhecimento da história do município pelo legislativo ao escolher os nomes dos logradouros; (2) a denominação dos logradouros não passar por nenhuma consulta à população; (3) as leis de nomeação dos logradouros não precisarem constar justificativa para escolha do nome; (4) a reprodução da sociedade machista, assim como em várias outros setores, se concretizar também na toponímia. 
Por fim, o estudo dos antropotopônimos, principalmente os femininos, merece a devida importância e é uma área que requer mais investigação em outras regiões do país a fim de que se torne possível verificar como a visibilidade feminina na toponímia se faz presente em outros territórios brasileiros, além de se ser uma forma de demonstrar a participação das mulheres no desenvolvimento de um município, principalmente nas áreas de saúde e educação, pilares de uma sociedade.

\section{Referências}

ANDRADE, K. S. Atlas toponímico de origem indígena do estado de Tocantins. Editora da PUC Goiás, 2010.

ARAÚJO, C., \& SCALON, C. (2005). Gênero, família e trabalho no Brasil. Rio de Janeiro: FGV, 2005.

BARROS, L. A. Curso Básico de Terminologia. (Acadêmica; 54). São Paulo: Editora da Universidade de São Paulo, 2004.

BBC. Women won't have equality for 100 years - World Economic Forum. 02 de nov. 2017. Disponível em: https://www.bbc.com/news/world-41844875. Acesso em: 11 jan. 2021.

BÍBLIA, A.T. Êxodo. In: A Bíblia Sagrada: tradução ecumênica. São Paulo: Paulinas, 2002. Cap. 1, vers. 15-17.

BOTELHO, Valéria. Pequena História das Irmãs Franciscanas Penitentes Recoletinas no Brasil. $2^{\text {a }}$ Ed. Belo Horizonte, Santa Cruz, 2007, p. 64.

CALHAU. In: Aulete digital. Dicionário contemporâneo da língua portuguesa. Lexikon Editora Digital, 2020. Disponível em: <http://www.aulete.com.br/calhau>. Acesso em: 15 jan. 2021.

CARDOSO, Armando Levy. Toponímia brasílica. Rio de Janeiro: Biblioteca do Exército Editora, 1961. 476p.

COSTA, Joaquim Ribeiro. Toponímia de Minas Gerais com Estudo da Divisão Territorial Administrativa. Belo Horizonte: Imprensa Oficial do Estado, 1970.

DICK, M. V. P. A. Toponímia e antroponímia no Brasil. Coletânea de Estudos. 2. ed. São Paulo: USP, 1990 a.

DICK, M. V. P. A. A Motivação Toponímica e a Realidade Brasileira. São Paulo: Edições Arquivo do listado, 1990 b. 
DICK, M. V. P. A. A Motivação Toponímica: Princípios teóricos c Modelos Taxionômicos. São Paulo: FFLCHAJSP, 1990c.

DICK, M.V.P.A. Método e questões terminológicas na Onomástica. Estudo de caso: a Toponímia do estado de São Paulo. Investigações - Linguística e Teoria Literária, São Paulo, v. 9, 1999.

FARIA, G.C.S. Tradição e memória: um estudo antroponímico dos nomes de logradouros da cidade de Ponte Nova. Tese. Universidade Federal de Minas Gerais, Belo Horizonte, 2017.

HEBERLE, M; MACHADO, N.T.G. As contribuições de Dick para o estudo da toponímia brasileira. Antares: letras e humanidades. Caxias do Sul, V.10 n²1. Set/Dez 2018. Disponível em: file:///C:/Users/Samsung/Downloads/6387-26170-1-PB.pdf Acesso em 25 de março de 2021.

INSTITUTO BRASILEIRO DE GEOGRAFIA E ESTATÍSTICA. Conheça as cidades e estados do Brasil - Araçuaí. IBGE, 2010. Disponível em: https://cidades.ibge.gov.br/. Acesso em: 10 jan 2020.

JONASSON, K. Le Nom Propre. Constructions et interprétations. De Boeck Superior, 1994.

KIEŁKIEWICZ - JANOWIAK,Agnieszka. Class, Age, and Gender-based Patterns. In: HERNÁNDEZ-CAMPOY, Juan Manuel; CONDE-SILVESTRE, Juan Camilo. The Handbook of Historical Sociolinguistics. Oxford, Wiley-Blackwell, $1^{\mathrm{a}}$ ed. 2012. p. 307331.

PEREIRA, L.O município de Araçuaí. Imprensa Oficial. Belo Horizonte, 1969.

PLATÃO. Os diálogos de Platão. Tradução de Carlos Alberto Nunes. v. IX: Teeteto Crátilo. Belém: Editora UFP, 1973.

SAINT-HILAIRE, A. Viagens pelas províncias do Rio de Janeiro e Minas Gerais. Editora Itatiaia, Belo Horizonte, 1975.

SAMPAIO, Teodoro. O tupi na geografia nacional. 5. ed. São Paulo: Companhia Editora Nacional, 1987.

SANTOS, Maria Salete Alves. Trajetória sóciopolítico das mulheres inseridas na política partidária em Araçuaí - MG: Conquistas e desafios. Monografia. Mariana MG. UFOP, 2012.

SOLIS FONSECA, G. La gente pasa, los nombres quedan. Introduccion en la Toponímia. Lima: Lengua y Sociedad, 1997. 
SOUZA, A.L. Confidências de mulheres in-visíveis do Jequitinhonha. Guaxupé, MG. Sato Alto Comunicações, 2011.

STEWART, G. R. A classification of place names. Names, Beckerley, v. II, n. 1, p. 113, mar. 1954.

WORLD ECONOMIC FORUM (WEF). Global Gender Index. 2017.

Recebido em: 18/01/2021

Aceito em: 27/03/2021

\begin{abstract}
${ }^{1}$ Isquerdo (1996: 118) apresenta uma subdivisão para a categoria dos animotopônimos em: eufórico (quando as lexias transmitem sensação agradável, expectativas otimistas como alegria, esperança, paz, entre outros) e disfórico (quando recuperam lexias que transmitem sensação desagradável, expectativas
\end{abstract} não otimistas como apertada, confusão, encrenca, entre outros).

${ }^{2}$ Nos últimos loteamentos de Araçuaí, foram os proprietários dos lotes que definiram os nomes dos logradouros.

${ }^{3}$ Bras. Pedra dura e solta de diferentes tamanhos (AULETE, 2020).

${ }^{4}$ Explicação ouvida de um morador antigo da cidade.

${ }^{5}$ Explicação ouvida de outro morador antigo da cidade.

${ }^{6}$ Maria Auxiliadora Colares Sá.

${ }^{7}$ Maria de Lourdes Cosenza Leite.

${ }^{8}$ Maria Miranda Cunha.

${ }^{9}$ Gislene Vieira Marcos.

${ }^{10}$ Embora conste na carta geográfica como Pacífica, o nome correto é Pacifique.

${ }^{11}$ Carmem da Cunha Melo.

12 Maria Ester Vieira Pinheiro.

${ }^{13}$ Aqui definido como grande fazendeiro, proprietário de muitas terras.

${ }^{14}$ Após o Concílio Vaticano II as irmãs tiveram permissão para voltarem seus nomes civis, pois antes ao ingressarem na vida religiosa precisavam escolher um nome diferente do civil. No Brasil apenas 01 irmã passou a usar seu nome civil.

${ }^{15}$ Cássia aparece acompanhada dos dois títulos: professora e irmã.

${ }^{16}$ A única das seis voluntárias que aparece como um topônimo na cidade de Araçuaí.

17 Irmã Pacifique chegou a Araçuaí em 1967, para trabalhar no Colégio Nazareth. Logo, ela se compadeceu dos idosos e mendigos abandonados na rua. Procurou ajuda e abrigo para essa gente. $\mathrm{O}$ resultado é que se desligou do Colégio Nazareth, dedicando-se totalmente àquilo que foi o início desta obra social, conforme relato da irmã Valéria. BOTELHO, Valéria.

${ }^{18}$ Conforme Lei Municipal de criação no 059/97, de 28 de novembro de 1997. 